\title{
Caracterização do uso de agrotóxicos entre trabalhadores rurais
}

\author{
Mayra Valéria Vasconcelos ${ }^{1}$ Cristiane Fonseca Freitas ${ }^{2}$ Cristiane Aparecida Silveira ${ }^{3}$
}

\begin{abstract}
RESUMO
Objetivo - caracterizar o perfil dos trabalhadores rurais que fazem uso de agrotóxicos em lavouras cafeeiras de Minas Gerais, identificando os riscos potenciais, sinais e sintomas indicativos da exposição. Método - estudo descritivo, epidemiológico, abordagem quantitativa, utilizando um instrumento estruturado testado e validado. Resultado - 91,07\% eram homens, $40 \%$ tinham idades entre 31 a 50 anos, 39,29\% tinham até 4 anos de estudo, 21,43\% não utilizavam o EPI sempre, 8,93\% foram intoxicados ao menos uma vez, 24,11\% foram treinados para uso do $\mathrm{EPI}$ ao manipular agrotóxicos. Dentre os sinais e sintomas descritos pelos trabalhadores rurais houve significativa relevância a queimação, irritabilidade, tosse, cefaleia, sede. Considerações finais - Os trabalhadores subestimam a relação do agrotóxico com os sinais e sintomas de intoxicação, dificultando a notificação. É preciso que os profissionais de saúde incorporem na sua prática a assistência integral à saúde dos trabalhadores englobando a prevenção, promoção, assistência de emergência e notificação.
\end{abstract}

Descritores: Trabalhadores rurais; Saúde do Trabalhador; Agrotóxicos; Promoção da Saúde.

\section{Characterization of pesticide use among farm workers}

\begin{abstract}
Objective - To characterize the profile of rural workers who use pesticides in coffee plantations in Minas Gerais, identifying potential risks, signs and symptoms indicative of exposure. Method - A descriptive study, epidemiological, quantitative approach, using a structured instrument tested and validated. Results $-91.07 \%$ were male, $40 \%$ were aged $31-50$ years $39.29 \%$ had 4 years of study, $21.43 \%$ were not wearing PPE always, $8.93 \%$ were intoxicated at least once, $24.11 \%$ were trained to use PPE when handling pesticides. Among the signs and symptoms described by rural workers was significant relevance to burning, irritability, cough, headache, thirst. Final consideration - The workers underestimate the relationship of the pesticide with the signs and symptoms of intoxication, making the notification. It is necessary that health workers to incorporate in your practice comprehensive care health workers encompassing prevention, promotion, emergency assistance and reporting.
\end{abstract}

Descriptors: Rural workers; Occupational Health; Pesticides; Health Promotion.

${ }^{1}$ Graduanda em Enfermagem na Pontifícia Universidade Católica de Minas Gerais (PUC Minas), Poços de Caldas, MG, Brasil.

2 Doutora em Famarcologia pela Universidade Estadual de Campinas (UNICAMP), Campinas, SP, Brasil.

${ }^{3}$ Doutora em Enfermagem pela Universidade de São Paulo (USP), São Paulo, SP, Brasil. 


\section{Introdução}

O risco ocupacional, as decisões e práticas de submeter-se ao mesmo encontram-se constantemente presentes no cotidiano das pessoas. Assim, no contexto nacional, em grande parte dos casos, os trabalhadores vivem no seu labor situações de riscos permanentes, pelo fato dos ambientes onde trabalham apresentarem-se inseguros e possuírem múltiplos agentes propiciadores de risco, seja físico, químico, biológico, psicológico e anti-ergonômico. ${ }^{1}$

As estatísticas oficiais mostram o crescimento do agronegócio nas últimas décadas. Entretanto, a crescente subordinação da produção agrícola à economia gera uma situação paradoxal: aumento e a diversificação da produção e surgimento de novas injúrias laborais ligadas ao uso do agrotóxico. ${ }^{2}$

Uma melhor compreensão dos fatores que determinam as práticas no uso de agrotóxicos tem sido buscada através da avaliação do nível de conhecimento e percepções dos trabalhadores rurais sobre o risco da exposição ocupacional, demonstrando que as intoxicações por agrotóxicos podem ser minimizadas à medida que o trabalhador compreende os riscos e segue os procedimentos de segurança necessários. ${ }^{3}$

Nos países em desenvolvimento, a exposição do trabalhador rural aos agrotóxicos se constitui em um grave problema de saúde pública, tanto pelo difícil acesso às informações, quanto pela baixa escolaridade dos usuários desses produtos, além da falta de controle sobre sua produção, distribuição e utilização. ${ }^{4}$

A linguagem técnica dos produtos e manuais é pouco acessível à maioria dos trabalhadores que lidam com estes produtos e os Equipamentos de Proteção Individual (EPI). Nem sempre os EPI estão adequados à realidade social, cultural, econômica e ao clima que os trabalhadores brasileiros enfrentam. ${ }^{4}$

A atenção integral à saúde do trabalhador necessita de uma interligação entre os diferentes níveis de atenção à saúde. Os profissionais de saúde devem atuar de forma multidisciplinar e pro-ativa, a fim de identificar os agravos, minimizar os danos causados pelo trabalho e desenvolver ações de promoção à saúde a estes trabalhadores. ${ }^{5}$

Diante do exposto, o objetivo do presente estudo caracterizar o perfil dos trabalhadores rurais que fazem uso de agrotóxicos em lavouras cafeeiras de Minas Gerais, identificando os riscos potenciais, sinais e sintomas indicativos da exposição.

\section{Metodologia}

Trata-se de um estudo com abordagem quantitativa, de caráter epidemiológico e descritivo, desenvolvida em um município do interior de Minas Gerais com 20.430 mil habitantes dos quais cerca de $77 \%$ ocupam a área urbana e 23\% ocupam a zona rural do município, segundo o censo demográfico de 2010 do Instituto Brasileiro de Geografia e Estatística. ${ }^{6}$

Neste estudo foram incluídos fazendas da região cafeeira do município, sujeitos do estudo 112 trabalhadores rurais.

Após aprovação dos proprietários das fazendas, o projeto foi aprovado pelo Comitê de Ética da Pontifícia Universidade Católica de Minas Gerais (CAAE 01845012.0.0000.5137), no dia 26/04/2012 respeitando-se a Resolução 466/12.7

Utilizou-se um instrumento tipo questionário estruturado, com perguntas fechadas, palavras de fácil entendimento dos trabalhadores, testado e validado.

Os dados quantitativos foram analisados estatisticamente, foi empregado análise de variância (ANOVA) seguido do Teste de Dunnett (software US. 04a Graphpad Instat, 1990), com valores de ${ }^{*} \mathrm{P}<0,05$ a ${ }^{* *} \mathrm{P}>0,01$ considerados significativos.

\section{Resultados}

Foram pesquisados 112 trabalhadores rurais. Os dados sociodemograficos são apresentados na Tabela 1. 
Tabela 1 - Caracterização dos trabalhadores rurais de um município mineiro, segundo dados biopsicossociais. Minas Gerais, 2013 ( $n=112)$.

\begin{tabular}{|c|c|c|c|}
\hline \multirow[t]{2}{*}{ Categorias } & \multirow[t]{2}{*}{ Variáveis } & \multicolumn{2}{|c|}{ Total } \\
\hline & & $f$ & $\%$ \\
\hline \multirow{5}{*}{ Idade } & $18-30$ anos & 40 & 35,71 \\
\hline & $31-50$ anos & 45 & 40,18 \\
\hline & Acima de 50 anos & 25 & 22,32 \\
\hline & Não responderam & 2 & 1,79 \\
\hline & Total & 112 & 100 \\
\hline \multirow{4}{*}{ Sexo } & Masculino & 102 & 91,07 \\
\hline & Feminino & 9 & 8,04 \\
\hline & Não responderam & 1 & 0,89 \\
\hline & Total & 112 & 100 \\
\hline \multirow{4}{*}{ Estado Civil } & Casado (a) & 61 & 54,46 \\
\hline & Solteiro (a) & 50 & 44,64 \\
\hline & Viúvo (a) & 1 & 0,89 \\
\hline & Total & 112 & 100 \\
\hline \multirow{9}{*}{ Escolaridade } & Analfabeto & 7 & 6,25 \\
\hline & $1^{\circ}$ a $4^{\circ}$ série EF & 44 & 39,29 \\
\hline & $5^{\circ}$ a 8 série EF & 41 & 36,61 \\
\hline & Ensino médio completo & 6 & 5,36 \\
\hline & $\begin{array}{l}\text { Ensino médio } \\
\text { incompleto }\end{array}$ & 7 & 6,25 \\
\hline & Ensino superior & 5 & 4,46 \\
\hline & Pós-graduado & 1 & 0,89 \\
\hline & Não responderam & 1 & 0,89 \\
\hline & Total & 112 & 100 \\
\hline \multirow{4}{*}{ Zona } & Rural & 39 & 34,82 \\
\hline & Urbana & 71 & 63,39 \\
\hline & Não responderam & 2 & 1,79 \\
\hline & Total & 112 & 100 \\
\hline
\end{tabular}

Fonte: Dados da pesquisa, 2013

Em relação à faixa etária, 45 (40,18\%) tem idades compreendidas entre 31 e 50 anos e 40 (35,71\%) entre 18 e 30 anos. Quanto ao sexo, $102(91,07 \%)$ eram homens e $9(8,04 \%)$ eram mulheres que desenvolviam alguma atividade envolvendo o uso de agrotóxico. Quanto ao estado civil, 61 (54,46\%) eram casados.

Na presente pesquisa, 6,25\% são analfabetos e 39,29\% tem até 4 anos de escolaridade; $39(34,82 \%)$ residem na zona rural o que na maioria das vezes torna-se um empecilho quanto ao estudo, locomoção, procura de auxílio médico, dentre outras dificuldades. 
Tabela 2 - Caracterização do trabalho dos trabalhadores rurais de um município mineiro, segundo condições de trabalho. Minas Gerais, 2013 ( $n=112)$.

\begin{tabular}{|c|c|c|c|}
\hline \multirow[t]{2}{*}{ Categorias } & \multirow[t]{2}{*}{ Variáveis } & \multicolumn{2}{|c|}{ Total } \\
\hline & & $\mathrm{F}$ & $\%$ \\
\hline \multirow{5}{*}{ Utilização do EPI } & Sim/ Sempre & 82 & 73,21 \\
\hline & Não/ Nunca & 13 & 11,61 \\
\hline & Às vezes & 11 & 9,82 \\
\hline & Não responderam & 6 & 5,36 \\
\hline & Total & 112 & 100 \\
\hline \multirow{5}{*}{$\begin{array}{l}\text { EPI fornecidos } \\
\text { pelo empregador }\end{array}$} & Sim & 85 & 75,89 \\
\hline & Não & 19 & 16,96 \\
\hline & Às vezes & 2 & 1,79 \\
\hline & Não responderam & 6 & 5,36 \\
\hline & Total & 112 & 100 \\
\hline \multirow{5}{*}{ Intoxicação } & Nenhuma vez & 99 & 88,39 \\
\hline & $1-2$ & 9 & 8,04 \\
\hline & $3-4$ & 1 & 0,89 \\
\hline & Não responderam & 3 & 2,68 \\
\hline & Total & 112 & 100 \\
\hline \multirow{4}{*}{ CAT } & Sim & 5 & 4,46 \\
\hline & Não & 23 & 20,54 \\
\hline & Não se aplica/Não responderam & 84 & 75 \\
\hline & Total & 112 & 100 \\
\hline
\end{tabular}

Fonte: Dados da pesquisa, 2013

Quanto às medidas de proteção ao trabalhador rural, fica notória a variação das concepções da qual este trabalhador tem sobre a utilização do EPI. Do total, 82 (73,21\%) relataram que sempre utilizavam EPI, $13(11,61 \%)$ nunca os utilizam e $11(9,82 \%)$ às vezes fazem uso dos mesmos. Porém, durante a pesquisa observou-se que muitos dos que assim relataram usá-los não os utilizavam ou se quer carregavam esses equipamentos.

Do total, $10(8,93 \%)$ relataram já ter se intoxicado pelo menos uma vez ao utilizar agrotóxico. Um deles já se intoxicou mais de 3 vezes. Dos que já se intoxicaram apenas 5 dos trabalhadores emitiram a Comunicação de Acidente de Trabalho (CAT), 23 não solicitaram a mesma. Outro fato preocupante é que 84 destes trabalhadores não responderam a questão relacionada a CAT, talvez por desconhecimento do que seja um acidente de trabalho.

Constatou-se que 10 (8,93\%) dos trabalhadores já sofreram algum tipo de intoxicação por agrotóxico, seja ela aguda ou crônica.

Para tentar identificar estas ocorrências, os trabalhadores foram questionados sobre se após usarem o agrotóxico constataram algum sinal/sintoma relacionado.

Gráfico 1 - Distribuição dos trabalhadores rurais de um município mineiro, segundo sinais e sintomas. Minas Gerais, $2013(n=112)^{*}$.
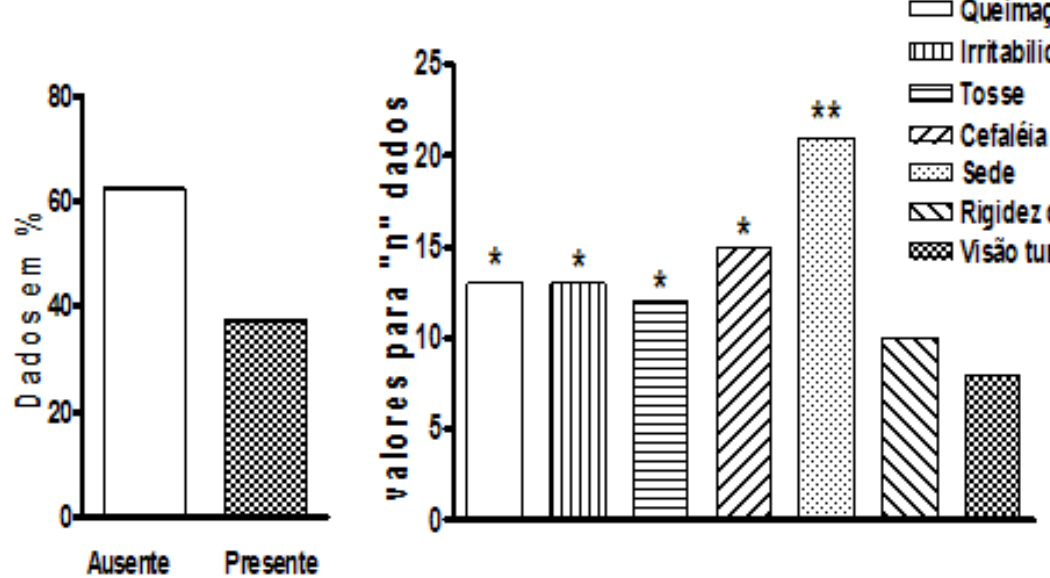

*Os valores são expressos em porcentagem para " $n$ " dados. ${ }^{*} P<0,05,{ }^{* *} P>0,01$ em relação ao grupo controle.

Fonte: Dados da pesquisa (2013) 
Em relação aos sinais e sintomas descritos pelos trabalhadores rurais foi constatado que houve uma predominância e significativa relevância a queimação $\left({ }^{*} P<0,05\right)$, irritabilidade $\left({ }^{*} P<0,05\right)$, tosse $\left({ }^{*} P<0,05\right)$, cefaleia $\left({ }^{*} P<0,05\right)$, sede $\left({ }^{* *} \mathrm{P}<0,01\right)$ e além destes a rigidez de nuca, visão turva, vômito, vertigens, insônia e alergia estiveram presentes em grande parte dos relatos. Assim, ao efetuar análise a partir do Teste de Dunnett, utilizou-se como comparação um grupo controle que representou um total de $62,5 \%$ dos trabalhadores que não apresentaram nenhum sinal ou sintoma e 37,5\% apresentaram, sendo que dentre estes $33,33 \%$ relataram três ou mais sintomas.

Gráfico 2 - Distribuição dos trabalhadores rurais de um município mineiro, segundo uso de EPI e sintomas. Minas Gerais, $2013(n=112)$.*

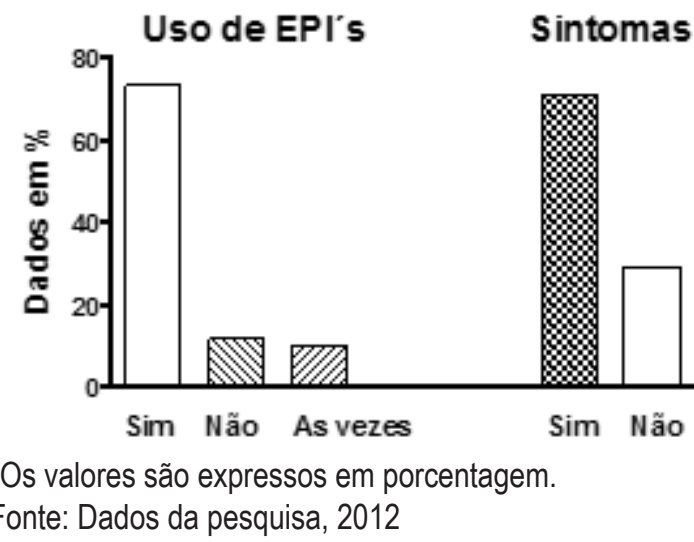

Logo, pode se observar que dentre os $21,47 \%$ dos indivíduos que não utilizavam o EPI ou às vezes faziam uso do mesmo, 70,43\% apresentaram algum sinal ou sintoma, o que demonstra a grande importância na utilização do EPI.

Tabela 3 - Distribuição dos trabalhadores rurais de um município do interior mineiro, segundo Educação permanente e exames admissionais. Minas Gerais, 2013 ( $n=112)$.

\begin{tabular}{c|c|c|c}
\hline \multirow{2}{*}{ Categorias } & Variáveis & \multicolumn{2}{|c}{ Total } \\
\cline { 2 - 4 } & & $f$ & $\%$ \\
\hline \multirow{4}{*}{ Treinamento para utilização de EPI } & Sim & 27 & 24,11 \\
\cline { 2 - 4 } & Não & 13 & 11,61 \\
\cline { 2 - 4 } & Não responderam & 72 & 64,29 \\
\cline { 2 - 4 } & Total & 112 & 100 \\
\hline \multirow{3}{*}{ Treinamento para manipular agrotóxico } & Sim & 27 & 24,11 \\
\cline { 2 - 4 } & Não & 13 & 11,61 \\
\cline { 2 - 4 } & Não responderam & 72 & 64,29 \\
\cline { 2 - 4 } & Total & 112 & 100 \\
\hline \multirow{5}{*}{ Exame de sangue (Colinesterase) } & Sim & 20 & 17,86 \\
\cline { 2 - 4 } & Não & 17 & 15,18 \\
\cline { 2 - 4 } & Não responderam & 75 & 66,96 \\
\cline { 2 - 4 } & Total & 112 & 100 \\
\hline
\end{tabular}

Fonte: Dados da pesquisa (2013)

Em relação ao treinamento para manuseio do agrotóxico $27(24,11 \%)$ receberam treinamento para utilização do EPI e manuseio de agrotóxicos, 13 (11,61\%) relataram que não e ignoraram a questão 72 (64,29\%) trabalhadores.

Em relação ao exame de sangue que avalia o nível de colinesterase, foi constatado que apenas $20(17,86 \%)$ dos trabalhadores efetuaram o exame. 


\section{Discussão}

Os dados sobre a faixa etária são coincidentes com os apresentados pela literatura que demonstram o uso de agrotóxicos por pessoas de todas as idades, sobretudo na agricultura familiar. ${ }^{8}$ Segundo a Norma Regulamentadora (NR) 31, os menores de 18 anos ou maiores de 60 anos não podem manusear agrotóxicos ou produtos afins ${ }^{9}$, proibição nem sempre respeitada.

Em um estudo realizado no Rio Grande do Sul (RS) sobre intoxicação por agrotóxicos, constatou-se que 47,5\% tinham idades compreendidas entre 20 e 39 anos com a significativa presença de adolescentes $(21,6 \%)^{3}$

$\mathrm{O}$ fator idade pode ocasionar um grave problema de saúde a estes trabalhadores que ficam expostos a estes agentes químicos, pois jovens e idosos estão mais suscetíveis ao adoecimento. Em um estudo realizado em Cachoeira do Sul - RS observou-se que os sintomas de boca seca, visão alterada e dor nas pernas foram mais prevalentes em idosos residentes na zona rural. ${ }^{10}$

Considerando o sexo dos trabalhadores rurais, nota-se a predominância masculina como o realizado no Rio Grande do Sul 62,2\% 3 e em Minas Gerais 95\% de homens ${ }^{11}$ e casados. Este fato, de maneira isolada não tem reflexo para a saúde. Entretanto, considerando o fenômeno da agricultura familiar e a "ajuda" esporádica da mulher e filhos, percebe-se o risco adicional para a saúde da família. Fato preocupante para a família como um todo, pois foi constatada a presença de agrotóxico até no leite materno. ${ }^{12}$

A questão da agricultura familiar pode ocasionar uma maior vulnerabilidade aos trabalhadores rurais que fazem uso dos agrotóxicos, alguns fatores acabam por ser impactantes à saúde dos mesmos, destacando-se a inexistência de uma efetiva fiscalização, controle e acompanhamento do poder público. Além disso, existe ainda o perfil dos trabalhadores rurais estudados que aponta a um baixo nível de escolaridade.

Em um estudo constatou-se que 46,7\% tinham de 1 a 4 anos de estudo. ${ }^{10}$ Assim, apesar de alfabetizados os trabalhadores não entendem o que está escrito, seja pela linguagem técnica, tamanho ou tipo de fonte. ${ }^{3,12}$

Além da questão da compreensão, há a percepção de riscos, a qual é influenciada por questões educacionais e/ ou culturais. $O$ fundamento da percepção de riscos está em imagens e crenças, pois cada pessoa possui experiências diferentes umas das outras, o que reflete na interpretação de situações futuras relacionadas ao agrotóxico. ${ }^{13}$

Os trabalhadores visualizam claramente o agrotóxico como fonte de ameaça e reconhece este, como um elemento negativo, que pode trazer uma situação de dano à sua saúde, à terceiros ou ao ambiente. Porém, a chamada invisibilidade de riscos leva ao descuido destes trabalhadores no cotidiano do seu labor. ${ }^{14}$

Além disso, a comunicação na zona rural é predominantemente oral e o fator cultural influencia fortemente na vida desta população. Logo, as mensagens visuais se tornam atrativo aos trabalhadores rurais, desde que adequadas ao repertório visual e intelectual dos mesmos. Portanto, a comunicação para o público rural necessita de um cuidado e um conhecimento refinado das características culturais e dos costumes regionais da população para que a mensagem possa ser compreendida. ${ }^{12}$

O uso, sem regularidade, do EPI tem diversa justificativas como "não possuírem esses equipamentos de proteção indicados", "não se preocuparem", "porque atrapalha" ou "por falta de orientação". ${ }^{4}$

Em um estudo desenvolvido na Armênia que analisava a utilização de EPI, constatou-se que houve uma predominância de uso incompleto dos EPI: $21,3 \%$ usavam luvas e apenas $11 \%$ relataram utilizar respiradores. ${ }^{15}$

Em outro estudo brasileiro, demonstrou-se que o uso de EPI por trabalhadores rurais idosos ocorre de forma incompleta com $85,4 \%$ dos mesmos e $45,1 \%$ descartam as embalagens de forma inadequada. ${ }^{10}$

Desta forma é importante não somente o fato de usar o EPI, mas usá-lo corretamente, pois, quando não usados de forma correta esses equipamentos podem se tornar mais uma fonte de contaminação e, nesse caso, acabam por propiciar uma falsa sensação de segurança. ${ }^{16}$

É necessária a conscientização destes trabalhadores, pois além da utilização correta do EPI, é importante a sua conservação, armazenamento, descarte em locais adequados, evitando o carregamento dos mesmos para suas residências.

Em um estudo realizado no Vale do São Francisco, $72 \%$ dos entrevistados relataram utilizar o EPI, nos que utilizavam de maneira incompleta, os principais EPI foram a máscara e luva. Os que não utilizavam o EPI estão entre os pequenos produtores e trabalhadores de pequenas propriedades. ${ }^{4}$ 
Além da não valorização do EPI, outro fator agravante para que o trabalhador não venha utilizar é a questão climática brasileira: o clima quente incomoda intensamente, o que leva a estes trabalhadores a não usarem estes equipamentos e/ou a usá-los de maneira incorreta. ${ }^{4}$

ANR 1 é relativa à segurança e medicina do trabalho, é de observância obrigatória pelas empresas privadas e públicas e pelos órgãos públicos da administração direta e indireta, bem como pelos órgãos dos Poderes Legislativo e Judiciário, que possuam empregados regidos pela Consolidação das Leis do Trabalho (CLT). Além do mais, cabe ao empregador cumprir e fazer cumprir as disposições legais e regulamentares sobre segurança e medicina do trabalho, elaborar ordens de serviço sobre segurança e saúde no trabalho, dando ciência aos empregados por comunicados, cartazes ou meios eletrônicos. ${ }^{17}$

Assim, a questão não se resume apenas em saber se os proprietários fornecem EPI aos seus trabalhadores, é necessário observar se os mesmos sabem utilizá-los, higienizá-los e guardá-los corretamente, pois estas normas muitas vezes são ignoradas, o que torna extremamente importante as informações e orientações sobre como utilizar os EPI, auxiliando a saúde, segurança do trabalho e prevenção de acidentes. ${ }^{16}$

Legalmente, segundo o Art. 19. da Lei 8213/91 ... acidente do trabalho é o que ocorre pelo exercício do trabalho a serviço da empresa, (...) provocando lesão corporal ou perturbação funcional que cause a morte ou a perda ou redução, permanente ou temporária, da capacidade para o trabalho. ${ }^{18}$

A Lista de Notificação Compulsória segundo a Portaria No 104/11, refere-se a doenças, agravos e eventos de importância para a saúde pública nacional, seja ela em rede de saúde pública ou privada. Estas doenças e eventos como em Anexo I n 23 Intoxicações Exógenas (por substâncias químicas, incluindo agrotóxicos, gases tóxicos e metais pesados) serão notificados e registrados no Sistema de Informação de Agravos de Notificação (SINAN). ${ }^{19}$

Desta forma, CAT é um instrumento de grande importância epidemiológica e uma fonte de informação em AT, sendo um instrumento previdenciário, há a necessidade do preenchimento do SINAN conforme Portaria 104/11, pois se trata de uma situação de intoxicação ocupacional. ${ }^{19}$

Em um estudo ao analisar a incidência de intoxicações por agrotóxicos no estado do Rio Grande do Sul através do SINAN, durante 5 anos constatou-se que a grande maioria dos casos ocorreram durante atividades relacionadas ao trabalho. Entretanto, somente 25 CAT foram emitidas. ${ }^{3}$

As informações que notificam os casos de intoxicações nem sempre correspondem ao total papel de vigilância, pois registram-se os casos agudos e/ou mais graves, deixando os demais casos na subnotificação, a qual segundo a Organização Mundial da Saúde (OMS), cada caso registrado corresponde a aproximadamente cinquenta eventos ocorridos. ${ }^{20}$

Muitos casos de subnotificação devem-se a dificuldade do próprio trabalhador reconhecer o evento como AT. Às vezes ao serem intoxicados ou eles não correlacionam com o uso do agrotóxico ou acham que é normal.

A intoxicação altera o estado de saúde de um indivíduo ou de um grupo de pessoas. É resultado da interação de substâncias com o organismo, podendo ocorrer de forma leve, moderada ou grave a depender da quantidade de veneno absorvido, do tempo de absorção, da toxicidade do produto e do tempo decorrido entre a exposição e o atendimento médico. ${ }^{21}$

Pressupõe-se que muitos trabalhadores subestimam a relação do agrotóxico com os sintomas, considerando a dor de cabeça, tontura e problemas de estômago como processos naturais decorrentes do seu trabalho, assim os sintomas subjetivos e constantes da exposição ocupacional podem ser um sinal precoce da intoxicação, o que pode afetar a qualidade de vida destes trabalhadores. ${ }^{22}$

Em outra pesquisa realizada em Goiás, observou-se que dentre os sintomas descritos pelos trabalhadores rurais estão a cefaléia, tontura, coceira, irritação nos olhos, enjoo, dor de estômago e vômito. ${ }^{16}$

As políticas de saúde partem do pressuposto de que o conhecimento e a prática têm uma relação direta entre si, assim suas ações são baseadas apenas para a transmissão de informações, passando a responsabilidade do cuidado da saúde para o indivíduo. Logo, observa-se que mesmo o trabalhador rural apesar de ter informações sobre 0 uso do agrotóxico e suas consequências, ele ainda o usa de forma indiscriminada e sem as proteções individuais legais. ${ }^{22}$

Para tanto, é necessário que haja uma educação continuada, que invista em ações de promoção da saúde, estando os profissionais da área articulados com as ações de prevenção e capacitados a identificar os casos de intoxicação por agrotóxicos. ${ }^{23}$

A NR7 e NR 31 estabelecem que todos os trabalhadores rurais devem realizar exames médicos ocupacionais, incluindo a avaliação dos riscos químicos, como os agrotóxicos. Sendo que para os agentes químicos organofosforados e 
carbamatos, são exigidas dosagens de colinesterase plasmática e/ou eritrocitária, considerando como valor de referência a atividade pré-ocupacional. .,24 $^{9}$

Os agrotóxicos são inibidores das colinesterases e podem ser absorvidos pela pele, ingestão ou inalação, inibindo as enzimas colinesterases eles proporciona um acúmulo de acetilcolina nas sinapses nervosas, ocasionando efeitos parassimpaticomiméticos. ${ }^{25}$

O exame de sangue pode medir o nível da enzima colinesterase que é um indicador da relação entre exposição a agrotóxico e problemas de saúde. Assim, a diminuição do teor da colinesterase pode permanecer por trinta dias e o das hemácias por noventa dias no organismo após o último contato com os agentes químicos. ${ }^{1}$

Faz-se necessário que o planejamento de estratégia seja contínuo, humano e totalmente integrado com os devidos setores relacionados ao tema, pois as mudanças de comportamento se dão a partir de médios e longos prazos. Além disso, a predominância da agricultura familiar analisada nesta pesquisa leva a constatar que é de suma importância um olhar voltado a família desses trabalhadores, para que assim eles possam usufruir de um conhecimento em que o leve a prevenção, proteção e promoção da familiares. ${ }^{8}$

\section{Considerações finais}

O não uso de EPI está intimamente ligado ao nível de intoxicação, o que nos leva a reflexão sobre a forma da qual as informações sobre a utilização, manuseio, transporte, acondicionamento e descarte são repassados aos trabalhadores, pois a maioria tem baixa escolaridade, o que pode influenciar no entendimento das bulas e rótulos dos agrotóxicos.

Percebeu-se também que os trabalhadores rurais subestimam a relação do agrotóxico com os sinais/sintomas, levando-os a estar mais propensos a intoxicação. A pesquisa demonstrou que sintomas subjetivos como irritabilidade, tosse, cefaleia, sede e problemas do estômago estão presentes no cotidiano destes trabalhadores, porém nem sempre são relacionados à intoxicação, não caracterizando-o como AT.

Desta forma, ocorre a dificuldade de subnotificação/notificação, o que leva a necessidade de melhor organização da assistência à saúde, de forma que capacitem os profissionais de saúde para a intervenção dos problemas relacionados ao uso de agrotóxicos.

É fundamental que os profissionais da saúde incorporem na sua prática cotidiana a compreensão de que o trabalho é um dos determinantes do processo saúde-doença e de que é necessário o envolvimento de todo o sistema de saúde para garantir o cuidado integral aos trabalhadores.

\section{Referências bibliográficas}

1. Mendes R. Patologia do trabalho. 3 ed. São Paulo: Atheneu, 2013. 769-808 p.

2. Batista Filho M, Melo MNT. Alimentação, Agrotóxicos e Saúde. Rev. Bras. Saúde Matern. Infant. jun. 2012 [acesso em 21 nov. 2013];12(2):113-19. Disponível em: http://www.scielo.br/scielo.php?script=sci_arttext\&pid=S1519$38292012000200001 \&$ Ing=en.

3. Barroso LB, Wolff DB. Riscos e segurança do aplicador de agrotóxicos no Rio Grande do Sul. Disc. Scientia. Série: Ciências Naturais e Tecnológicas, S. Maria, 2009 [acesso em 21 nov. 2013];10(1):27-52. Disponível em: http://sites.unifra. br/Portals/36/tecnologicas/2009/completos/03.pdf

4. Bedor CNG, Ramos LO, Pereira PJ, Rêgo MAV, Pavão AC, Augusto LGS. Vulnerabilidades e situações de riscos relacionados ao uso de agrotóxicos na fruticultura irrigada. Rev. bras. epidemiol. mar. 2009 [acesso em 21 nov. 2013]; 12(1):39-49.Disponível em: http://www.scielo.br/scielo.php?script=sci_arttext\&pid=S1415790X2009000100005\&lng=en.

5. Mantovani MF, Lacerda MR, Ulbrich E, Bandeira JM, Gaio DM. Panorama da produção do conhecimento em enfermagem na saúde do trabalhador: impacto e perspectivas. Rev. bras. enferm. out. 2009 [acesso em 21 nov. 2013];62(5):784-88. Disponível em: http://www.scielo.br/scielo.php?script=sci_arttext\&pid=S0034-71672009000500024\&Ing=en

6. Instituto Brasileiro de Geografia e Estatística (IBGE). Censo 2010 [acesso em: 14 abr. 2013]. Disponível em: http:// www.censo2010.ibge.gov.br/sinopse/index.php?uf=31\&dados=1 
7. Conselho Nacional de Saúde. Resolução 466. Estabelece Diretrizes e Normas Regulamentadoras envolvendo Seres Humanos. Brasília, 12 de dezembro de 2012 [acesso em: 22 mai. 2013]. Disponível em: http://conselho.saude.gov.br/ resolucoes/2012/Res0466.pdf

8. Brito PF, Gomide M, Camara VM. Agrotóxicos e saúde: realidade e desafios para mudança de práticas na agricultura. Physis 2009 [acesso em 21 nov. 2013]; 19(1): 207-25. Disponível em: http://www.scielo.br/scielo.php?script=sci_ arttext\&pid=S0103-73312009000100011\&Ing=en

9. Ministério do Trabalho e Emprego (BR). Portaria MTE n. ${ }^{8}$ 86, de 03 de março de 2005. NR 31 - Segurança e saúde no trabalho na agricultura, pecuária silvicultura, Exploração florestal e aquicultura. [acesso em: 04 abr. 2013]. Disponível em: http://portal.mte.gov.br/data/files/8A7C812D33EF459C0134561C307E1E94/NR-31\%20(atualizada\%202011).pdf

10. Silva EF, Paniz VMV, Laste G, Torres ILS. Prevalência de morbidades e sintomas em idosos: um estudo comparativo entre zonas rural e urbana. Ciênc. saúde coletiva . 2013 [acesso em 21 nov. 2013];18(4):1029-1040. Disponível em: http://www.scielo.br/scielo.php?script=sci_arttext\&pid=\$1413-81232013000400016\&lng=en

11. Silva VC. Uso de Agrotóxicos nas Lavouras de Café do Município de Campos Gerais. [monografia] Campos Gerais: Universidade Federal de Minas Gerais; 2012. 66 p.

12. Yamashita MGN. Análise de rótulos e bulas de agrotóxicos segundo dados exigidos pela legislação federal de agrotóxicos e afins e de acordo com parâmetros de legibilidade tipográfica. [dissertação] Bauru: Universidade Estadual Paulista - UNESP; 2008. 21-186 p.

13. Mendes SAF, Silva Junior MF. Percepção de risco no uso de agrotóxicos na produção de tomate do distrito de nova matrona, Salinas, Minas Gerais. CAMINHOS DE GEOGRAFIA - Revista online set. 2011 [acesso em 21 nov. 2013]12(39):226-44. Disponível em: http://www.biblioteca.uesc.br/biblioteca/bdtd/200860187D.pdf

14. Gregolis TBL, Pinto WJ, Peres F. Percepção de Riscos fazer uso de agrotóxicos por Trabalhadores da Agricultura Familiar do Município de Rio Branco, AC. Rev. bras. Saúde Ocup. jun. 2012 [acesso em 21 nov. 2013]; 37(125). Disponível em: http://www.scielo.br/scielo.php?script=sci_arttext\&pid=S030376572012000100013\&lng=en\&nrm=iso

15. Tadevosyan A, Tadevosyan N, Kelly K, Gibbs SG, Rautiainen RH. Pesticide use practices in rural armenia. J Agromedicine. 2013;18(4):326-33.

16. Alves SMF, Fernandes PM, Marin JOB. Condições de trabalho associadas ao uso de agrotóxicos na cultura de tomate de mesa em Goiás. Ciênc. agrotec. 2008 [acesso em 21 nov. 2013];32(6):1737-42. Disponível em: http://www.scielo.br/ scielo.php?script=sci_arttext\&pid=S1413-70542008000600009\&lng=en\&nrm=iso

17. Ministério do Trabalho e Emprego (BR). Portaria SIT n. ${ }^{\circ} 84$, de 04 de março de 2009. Disposições Gerais. [acesso em: 02 mai. 2013]. Disponível em: http://portal.mte.gov.br/data/files/FF8080812BE914E6012BEF0F7810232C/nr_01_at.pdf

18. Brasil. Lei $n^{0} 8.213$, de 24 de julho de 1991. Dispõe sobre os Planos de Benefícios da Previdência Social e dá outras providências. Brasília, 24 jul. 1991 [acesso em: 28 abr. 2013]. Disponível em: http://www.planalto.gov.br/ccivil_03/leis/ I8213cons.htm

19. Mistério da Saúde (BR). Portaria n. ${ }^{0} 104$, de 25 de janeiro de 2011. Define as terminologias adotadas em legislação nacional, conforme o disposto no Regulamento Sanitário Internacional 2005 (RSI 2005), a relação de doenças, agravos e eventos em saúde pública de notificação compulsória em todo o território nacional e estabelece fluxo, critérios, responsabilidades e atribuições aos profissionais e serviços de saúde. Diário Oficial da União. Brasília, 26 janeiro 2011 [acesso em: 28 abr. 2013]. Disponível em: http://portal.saude.gov.br/portal/arquivos/pdf/portaria_104_26_2011_dnc.pdf 20. Navolar TS, Rigon SA, Philippi JMS. Diálogo entre agroecologia e promoção da saúde. Rev. Bras. em Promoção da Saúde nov. 2009 [acesso em 21 nov. 2013];23(1) Disponível em: http://ojs.unifor.br/index.php/RBPS/article/view/1176 21. Ministério da Saúde (BR). Sistema Nacional de Informações Tóxico Farmacológicas - SINITOX. Casos Registrados de Intoxicação Humana por Agente Tóxico e Centros dos Estados de Minas Gerais, Espírito Santo e Rio de Janeiro, 2010 [acesso em: 14 abr. 2013]. Disponível em: http://www.fiocruz.br/sinitox_novo/cgi/cgilua.exe/sys/start.htm?sid=318 22. Hoshino ACH, Pacheco FH, Taguchi CK, Tomita S, Miranda MF. A auto-percepção da saúde auditiva e vestibular de trabalhadores expostos a organofosforados. Rev. CEFAC dez. 2009 [acesso em 21 nov. 2013];11(4):681-87. Disponível em: http://www.scielo.br/scielo.php?script=sci_arttext\&pid=S151618462009000800017\&lng=en

23. Machado LM. O cuidado da equipe de estratégia de saúde da família a trabalhadores rurais expostos a agrotóxicos. [dissertação]. Santa Maria, RS: Universidade Federal de Santa Maria; 2012. 14-99 p.

24. Ministério do Trabalho e Emprego (BR). Portaria SSST n. ${ }^{\circ} 24$, de 29 de dezembro de 1994. Normas Regulamentadoras de Segurança e Saúde no Trabalho (NRs) NR 7 - Programa de controle médico de saúde ocupacional. 1994 [acesso em: 28 abr. 2013]. Disponível em: http://portal.mte.gov.br/data/files/8A7C812D308E21660130E0819FC102ED/nr_07.pdf 
25. Organização Pananamericana de Saúde. Manual de vigilância da saúde de populações expostas a agrotóxicos. Brasília, 1996 [acesso em: 03 mai. 2013]. Disponível em: http://bvsms.saude.gov.br/bvs/publicacoes/livro2.pdf

\section{Cristiane Aparecida Silveira}

Endereço para correspondência - Rua Erechim, 1456, apto 05. Bairro Centro, CEP: 85812-260, Cascavel, PR, Brasil.

E-mail: casilve@yahoo.com.br

Lattes: http://lattes.cnpq.br/4190390095539722

Mayra Valéria Vasconcelos - mayrahandball@hotmail.com

Cristiane Fonseca Freitas - cfreitas@pucpcaldas.br

\section{Enviado em 26 de novembro de 2013.}

\section{Publicado em 15 de setembro de 2014.}

